\title{
An Assessment of Vehicular Emissions and Related Health Impacts along Ilorin-Lagos Highway in Nigeria
}

\author{
Modinah A.O. Abdul Raheem*, Kamaldeen O. Ajayi, Olanrewaju A. Awoyemi
}

Department of Chemistry, Faculty of Physical Sciences, University of Ilorin, Ilorin, Nigeria

Received $1^{\text {st }}$ August, 2019, Accepted $4^{\text {th }}$ November, 2019

DOI: 10.2478/ast-2019-0013

*Corresponding author

Modinah A.O.Abdul Raheem E-mail:modinah4@yahoo.co.uk amadenike@unilorin.edu.ng

Tel: $+234-8035952356$

\begin{abstract}
This paper assessed in-vehicle and ambient pollution levels from vehicles along Ilorin-Lagos highway covering three distinct 3-hour periods (morning, afternoon and evening) of the day (from 7.30 am to $6.30 \mathrm{pm}$ ) along with reported health challenges at six (6) settlements (SP1-SP6) that covered four (4) states. In the case of ambient pollution, Gilair-3 air sampler (GAS) was used to measure sulphur (iv) oxide, $\left(\mathrm{SO}_{2}\right)$ while ALTAIR $5 x$ Multi-gas Detector (AMD) was used to measure both carbon (ii) oxide, ( $\mathrm{CO})$ and sulphur (iv) oxide, $\left(\mathrm{SO}_{2}\right)$ for all scenarios. Vehicular volume was manually conducted to determine the number of vehicles. Questionnaire was used to assess information on the health challenges faced by the commuters. The concentrations of $\mathrm{SO}_{2}$ ranged from $0.142-0.550 \mathrm{ppm}$ (ambient) and 0.037 - 0.097 ppm (in vehicle) using AMD and GAS respectively while CO concentration was between 2.289 - 18.055 ppm using AMD. The results for the in- vehicular pollution revealed that the concentration levels obtained for CO and $\mathrm{SO}_{2}$ inside the vehicles were $6.32 \mathrm{ppm}$ and $0.126 \mathrm{ppm}$ under opened-window condition and $9.53 \mathrm{ppm}$ and 0.274 ppm under closed-window condition respectively (without air condition). The $\mathrm{SO}_{2}$ concentrations obtained from both ambient and in-vehicle were found to be much higher when compared with the FEPA standards; $\mathrm{SO}_{2}(0.01-$ $0.1 \mathrm{ppm})$, USEPA standards; $\mathrm{SO}_{2}(0.075 \mathrm{ppm})$ while the $\mathrm{CO}$ level obtained from in-vehicle under the two scenarios (opened and closed windows) were below the limit of NESREA standards (10 - $20 \mathrm{ppm})$ and USEPA standards (35 ppm). Having noticed that these pollutants act under different environmental conditions, the work established statistical evidence that traffic volume affected the pollutants concentrations at most of the sampling points and that the higher the traffic, the higher the emissions and the more the risk of health challenges.
\end{abstract}

Keywords: Pollution, Carbon (iv) oxide, Sulphur (iv) oxide, Gilair-3, Altair-5x, , automobiles 


\subsection{Introduction}

Air pollution is the introduction into the atmosphere of chemicals, particulates, or biological materials that cause discomfort, disease, or death to humans, damage other living organisms such as food crops, or damage the natural environment or environment. The atmosphere is a complex dynamic natural gaseous system that is essential to support life on planet Earth. Stratospheric ozone depletion due to air pollution has long been recognized as a threat to human health as well as to the Earth's ecosystems. The major sources of air pollution are transportation engines, power and heat generation, industrial processes, and the burning of solid waste (Sharma et al., 2013).

Exposures to traffic related air pollutants have been shown to cause a number of adverse health effects ranging from chronic conditions such assystemic inflammation to acute conditions such as alterations in heart rate variability and myocardial infarction (Dominici et al., 2006; Peters, 2004; Pope et al., 2015; Tonne et al., 2007). Therefore, it is important to understand the mechanisms governing air pollutant exposures occurring in various commute microenvironments such as private transportation, rail, bus, and active transport (Ham et al., 2017). It has been shown that concentrations of air pollutants on or near roadways are typically enhanced above background concentrations (Zhu et al., 2002). Gas-phase and particle phase traffic related air pollutants may be up to ten times greater than those measured at ambient monitoring stations potentially resulting in increased exposure concentrations in microenvironments near roadways (Zhu et al., 2002). However, in-vehicle concentrations are highly variable and depend upon many factors including travel mode, meteorology, fleet mix, traffic parameters, fuel type, cabin ventilation, exhaust treatment, filtration, deposition, and other factors (Delfino and $\mathrm{Wu}, 2012$ ). Furthermore, air pollution is considered a major threat to human health because of its link to an increased mortality and loss of disability-adjusted life years (Rivas et al., 2017).

Incomplete combustion of hydrocarbon (HC) fuels causes vehicular emissions. The combustion of HC fuels however, has the potential of producing oxides of sulphur, oxides of carbon which can combine with water in the atmosphere to form acids of sulphur and carbon These oxides produced as a result of inefficient combustion of HC fuels is highly toxic even at small levels of concentration, and has been known to decrease human efficiency. However, studies conducted to identify a causal relationship between urban pollution and an exacerbation of asthmatic bronchial reactivity in asthma patients have yielded contrasting results: some Authors (Zmirou et al., 2004, Ebtekar, 2006 and Estevez-Garcia et al., 2013), reported an increased disease burden with exacerbation of the asthma attacks on days when the levels of ozone and other pollutants were higher while others found no increased prevalence rate of asthma (Biggeri et al., 2004).

In most developing countries of the world; vehicular growth has not been checked properly by environmental regulating authorities leading to increased levels of pollution (Han and Naeher, 2006). The health challenges experienced by travellers, road users, passers-by, residents and business operators in traffic flash points, having high concentration of vehicular traffic during some periods of the day are worrisome. In Nigeria, the increasing trend of importing used vehicles is contributing to air pollution and degradation of the environment despite the global efforts to reduce environmental problems caused by mobile transportation (Ajayi and Dosunmu, 2002; Atubi, 2015). Pollution from mobile transportation is on the increase as the number of vehicle owners is increasing, coupled with bad roads which is causing high congestion on roads in cities and increasing the levels of air pollutants, consequently, increasing health problems in human population.

According to the United States Environmental Protection Agency (USEPA, 2006), motor vehicles account for $10 \%$ of particulate matter (PM), $34 \%$ of nitrogen dioxide $\left(\mathrm{NO}_{2}\right)$, and $51 \%$ of carbon monoxide (CO) released yearly in the US. Similarly, the World Health Organization, WHO (2001) has identified motor vehicle as one of the major leading causes of air pollution in most urban cities of the world, though China, United States, Russia, Mexico, and Japan are the world leaders in air pollution emissions.. This clearly indicates that motor vehicle emission is a major source of air pollution in both developed and developing countries.

Most researches carried out were assessing the ambient air which may not really indicate the concentrations of pollutants in vehicle while the commuters are on. This study therefore, assessed the concentrations of $\mathrm{SO}_{2}$ and $\mathrm{CO}$ in an opened and closed windows scenario of travelling vehicles while travelling and at the ambient concentrations of these pollutants at major settlements along the path of the Ilorin- Lagos highway.

\subsection{Materials and Method}

The vehicular indoor and ambient concentrations of $\mathrm{SO}_{2}$ and $\mathrm{CO}$ along Ilorin-Lagos highway were measured. MSA Altair $5 \mathrm{x}$ multi gas sensor was used for the in-vehicle measurements of $\mathrm{SO}_{2}$ and $\mathrm{CO}$, while Gilair3 air sampling pump was used to measure the ambient concentrations of $\mathrm{SO}_{2}$. The results were compared with the safe limits set by FEPA standards; $\mathrm{SO}_{2}$ (0.01 ppm for 1-hour limit and $0.1 \mathrm{ppm}$ for 24-hour limit), USEPA standards; $\mathrm{SO}_{2}$ (0.075 ppm hourly limit) while the $\mathrm{CO}$ level obtained from both vehicular outdoor and indoor pollutions were within the limit of NESREA standards (10 ppm for 1-hour limit and 20 ppm for 8-hour limit) and USEPA standards (35 ppm for 1-hour limit) and the health implications of these pollutants on the road users were also assessed using questionnaire.

\subsection{The study Area}

This research was conducted at six (6) sampling points along IlorinLagos highway covering six settlements in four (4) states (Kwara, Oyo, Ogun and Lagos states) in Nigeria. This highway connects the Northern part of Nigeria to the South west of the country. Figure 1 shows the sampling points along Ilorin-Lagos highway where there are settlements.

The selected locations, points and coordinates are shown in the table 1: 


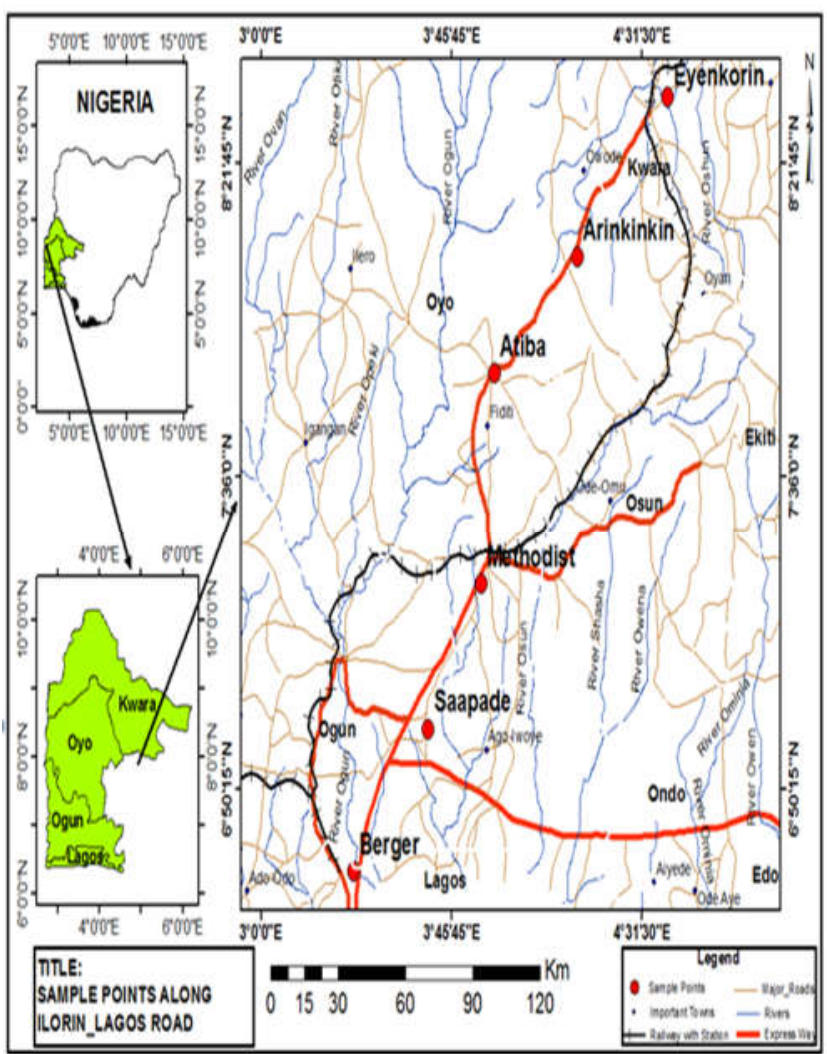

Figure 1: Map of the highway under study (Ilorin-Lagos ) showing all the sampling points.

Table 1: Selected locations and sampling points

\begin{tabular}{|cccc|}
\hline S/No. & $\begin{array}{c}\text { SELECTED } \\
\text { LOCATIONS }\end{array}$ & SAMPLING POINTS & GPS \\
\hline 1 & Ilorin & Eyenkorin (SP1) & $8.523^{\circ} \mathrm{N}, 4.629^{\circ} \mathrm{E}$ \\
2 & Ogbomoso & Arinkinkin (SP2) & $8.133^{\circ} \mathrm{N}, 4.267^{\circ} \mathrm{E}$ \\
3 & Oyo & Atiba (SP3) & $7.850^{\circ} \mathrm{N}, 3.933^{\circ} \mathrm{E}$ \\
4 & Ibadan & Methodist Oritamefa & $7.334^{\circ} \mathrm{N}, 3.879^{\circ} \mathrm{E}$ \\
& & $(S P 4)$ & \\
5 & Saapade & Saapade (SP5) & $6.982^{\circ} \mathrm{N}, 3.666^{\circ} \mathrm{E}$ \\
6 & Lagos & Bergger (SP6) & $6.635^{\circ} \mathrm{N}, 3.367^{\circ} \mathrm{E}$ \\
\hline
\end{tabular}

\subsection{Period of sampling, frequency and duration}

The time frame for data collection of ambient pollutants for the six (6) sampling points was carried out within unique 3-hour periods of the day (morning, afternoon and evening) for duration of three days at each sampling point. This covered comprehensive vehicles movement within the days at the sampling points. These times were categorized as follows:

(i) $7.30 \mathrm{am}-10.30 \mathrm{am}$ morning peak hours (ii) 11.30 am -2.30 pm off-peak hours

(iii) $3.30 \mathrm{pm}-6.30 \mathrm{pm}$ evening peak hours

\section{$2.3 \mathrm{CO}_{2}$ and $\mathrm{SO}_{2}$ Data Collection Using MSA Altair 5x Multi Gas Sensor}

The air pollutants ( $\mathrm{CO}$ and $\mathrm{SO}_{2}$ ) were measured with MSA Altair $5 \mathrm{x}$ multi gas sensor, a unique and portable multi-gas monitor for detection of $\mathrm{CO}, \mathrm{SO}_{2}, \mathrm{NO}_{2}$ and flammable gases. Although, the latter two species are not reported in this work. This multi-gas detector is flexible, robust, portable, and intrinsically safe. It has embedded software that is designed to meet the requirements of International Electrotechnical Commission (IEC 61508-3).

The Altair $5 \mathrm{x}$ were pre-calibrated by the instrument manufacturer and all measurements are reported in units of ppm. On arrival at the field, MSA altair 5x sampler unit was first of all switched on in a clean environment in order to perform bump test and calibration test, this zero the sampler unit. MSA altair $5 \mathrm{x}$ then display the sensor and calibration information and this complete the fresh air setup. The sensor described above was used for outdoor sampling by measuring the pollutants for every 15 minutes interval at a point located $2 \mathrm{~m}$ away from the road edge at each sampling point located along the route under study and it was used also inside the travelling vehicle for indoor sampling.

Motor traffic count was conducted manually to obtain the volume of traffic at the sampling points. Both to and fro travelling motor vehicles were counted. The counting was done within the space of 45 minutes so as to avoid repetition.

\section{4 $\mathrm{SO}_{2}$ Data Collection Using Gilair-3 Air Sampling Pump}

All samples were taken by bubbling gases through a specific buffered absorbing reagent $\left(0.3 \mathrm{M} \mathrm{H}_{2} \mathrm{O}_{2}\right)$ conditioned to $\mathrm{pH}$ of 5 . This is a $\mathrm{SO}_{2}$ chemically selective absorbing solution using gilair-3 air sampler. The sampler had adjustable flow-meter part which was used to measure the volume of air that is drawn through the absorbing solution. A low flow rate was maintained because it ensures smaller bubbles which in turn allow more surface contact between the gas and absorbing solution and a higher efficiency of gas absorption results (Abdul Raheem et al., 2009).

\subsubsection{Procedure for sampling $\mathrm{SO}_{2}$ (Hydrogen Peroxide Method)}

$0.3 \mathrm{M} \mathrm{H}_{2} \mathrm{O}_{2}$ absorbing reagent was prepared from $30 \%$ stock solution. $25 \mathrm{ml}$ was taken from it and poured into a $100 \mathrm{ml}$ standard flask containing $3.4 \mathrm{~g}$ of Potassium dihydrogen phosphate $\left(\mathrm{KH}_{2} \mathrm{PO}_{4}\right)$ and 3.6 $\mathrm{g}$ of disodium hydrogen phosphate $\left(\mathrm{Na}_{2} \mathrm{HPO}_{4}\right)$, the whole volume was brought to the mark with double distilled water.

The $\mathrm{pH}$ of this solution was maintained at 5.0 using dilute $\mathrm{HCl}$ to prevent CO interferences (Abdul Raheem et al., 2009).

At the sampling point, the bubbler was then filled with $20 \mathrm{ml}$ of the prepared absorbing reagent which was sufficient to last for 3 hours sampling. The sampling train was prepared by placing the bubbler in its compartmental system securely connected to the manifold and the inlet and outlet. 


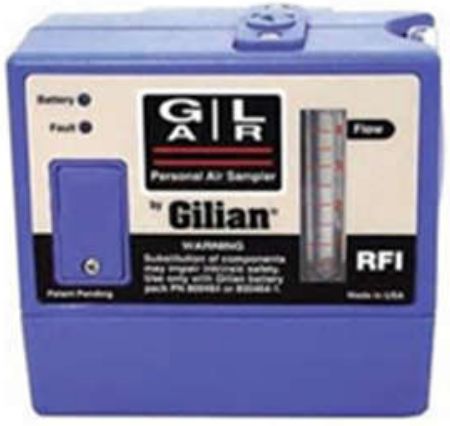

Figure 2: Gilair-3 Air sampling train

The sampler was put on while the flow rate was adjusted to $1.5 \mathrm{~L} / \mathrm{min}$. The conductivity of the absorbing reagent was measured with a conductivity metre immediately after the sampling.

$\mathrm{H}_{2} \mathrm{O}_{2}(\mathrm{l})+\mathrm{SO}_{2}(\mathrm{~g}) \rightarrow \mathrm{H}_{2} \mathrm{SO}_{4}(\mathrm{aq})$

From the standardized concentration of $\mathrm{H}_{2} \mathrm{SO}_{4}(0.1 \mathrm{M})$, different concentrations ranging from 0.0017 to $0.1 \mathrm{M}$ were prepared using serial dilution. Conductivity of these solutions of known concentrations was determined using Hanna conductivity meter. The data generation were used to produce a calibration curve using excel data sheet. The calibration curve obtained was used as a working curve for the determination of $\mathrm{SO}_{2}$ during the analysis of samples (Abdul Raheem et al., 2009).

The concentrations of $\mathrm{SO}_{2}$ were obtained in ppm using the formula below:

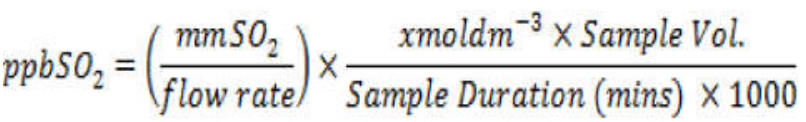

ppm $\mathrm{SO}_{2}=1 \times 10^{-3 *} \mathrm{ppb}$

$\mathrm{mm} \mathrm{SO}_{2}=$ molar mass of $\mathrm{SO}_{2}(64 \mathrm{~g} / \mathrm{mol})$

$\mathrm{x}$ moldm${ }^{-3}=$ is the concentration of $\mathrm{SO}_{2}$ extrapolated from the calibration curve

Sample $\mathrm{Vol}=$ volume of absorbing reagent

Sample Duration = Duration of sampling

\subsection{Questionnaire}

A questionnaire was developed in order to assess the information from the road users (commercial drivers) to get detailed information on their vehicles and how they maintained them coupled with health challenges sustained as a result of pollution. Information collected as part of the questionnaire includes; gender, age, years worked, ownership of household generator, and smoking status. Health conditions such as cough, poor breathing, chest pain, headache, etc were also collected.

Also, information on the vehicle such as: name of vehicle, name of engine lubricant, engine service duration, frequency of ringing the engine or number of times of replacement of the engine were collected for correct assessment of the vehicle.

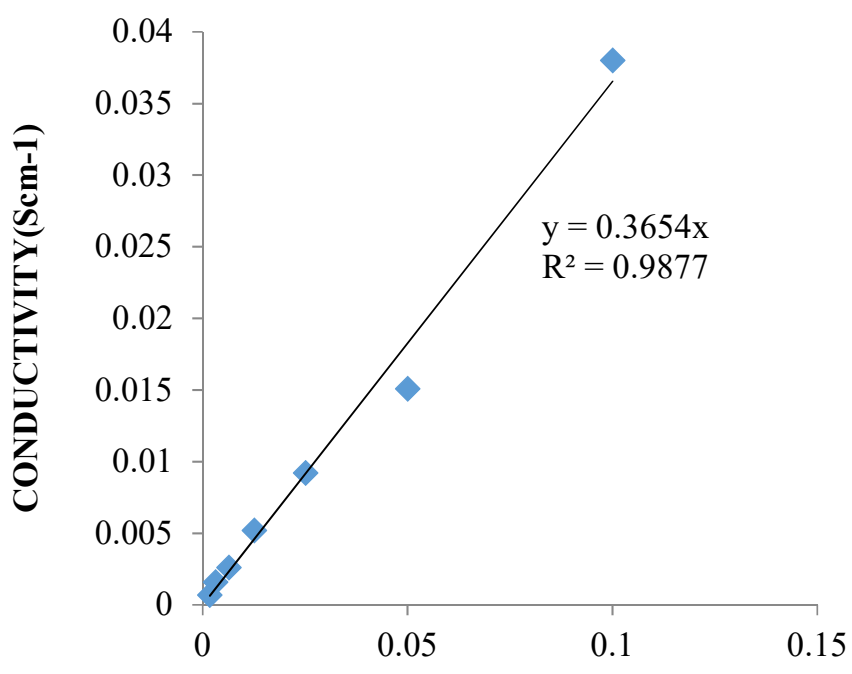

CONCENTRATION (moldm-3)

Figure 3: $\mathrm{SO}_{2}$ calibration curve

\subsection{Results}

Altair $5 \mathrm{x}$ multi gas sensor was used for in-vehicle measurements of $\mathrm{CO}$ and $\mathrm{SO}_{2}$ in ppm and the average traffic volume was manually counted. These are reported in Table 2; Table 3:

Average traffic volume and average $\mathrm{SO}_{2}$ concentrations obtained in ppm using gilair-3 air sampler; Table 4: Health problems perceived by the users of the road under study; Figure 4: Mean carbon (ii) oxide (CO) levels across periods at the six (6) sampling points using MSA Altair 5x multi gas sensor; Figure 5: Daily mean of carbon (ii) oxide (CO) levels per three days at each sampling point using altair $5 \mathrm{x}$ multi gas sensor; Figure 6: Mean sulphur (iv) oxide $\left(\mathrm{SO}_{2}\right)$ levels across periods at the six (6) sampling points using MSA Altair 5x multi gas sensor; Figure 7: Daily mean of sulphur (iv) oxide $\left(\mathrm{SO}_{2}\right)$ levels per three days at each sampling point using altair $5 \mathrm{x}$ multi gas sensor; Figure 8: Mean sulphur (iv) oxide $\left(\mathrm{SO}_{2}\right)$ levels across periods at the three (3) sampling points using gilair 3 air sampler; Figure 9: Daily mean of sulphur (iv) oxide $\left(\mathrm{SO}_{2}\right)$ levels per three days at each sampling point using gilair 3 air sampler; Figure 10: The various health problems perceived by the respondents of the questionnaires and their frequencies. 
Table 2: Average traffic volume and average $\mathrm{CO}$ and $\mathrm{SO}_{2}$ concentrations obtained in ppm using altair $5 \mathrm{x}$ multi gas sensor

\begin{tabular}{|c|c|c|c|c|c|c|c|c|c|}
\hline Sampling & Morning & & & Afternoon & & & Evening & & \\
\hline & $\begin{array}{l}\text { Average } \\
\text { Traffic } \\
\text { volume }\end{array}$ & $\begin{array}{l}\text { Mean } \\
\text { CO } \\
(\mathrm{ppm})\end{array}$ & $\begin{array}{l}\text { Mean } \\
\mathrm{SO}_{2} \\
(\mathrm{ppm})\end{array}$ & $\begin{array}{l}\text { Average } \\
\text { Traffic } \\
\text { volume }\end{array}$ & $\begin{array}{l}\text { Mean } \\
\text { CO } \\
(\mathrm{ppm})\end{array}$ & $\begin{array}{l}\text { Mean } \mathrm{SO}_{2} \\
(\mathrm{ppm})\end{array}$ & $\begin{array}{l}\text { Average } \\
\text { Traffic } \\
\text { volume }\end{array}$ & $\begin{array}{l}\text { Mean } \\
\text { CO } \\
(\mathrm{ppm})\end{array}$ & $\begin{array}{l}\text { Mean } \mathrm{SO}_{2} \\
(\mathrm{ppm})\end{array}$ \\
\hline SP1 & 397 & 5.479 & 0.465 & 366 & 4.663 & 0.355 & 432 & 18.055 & 0.55 \\
\hline SP2 & 695 & 4.561 & 0.372 & 660 & 3.798 & 0.368 & 677 & 4.675 & 0.371 \\
\hline SP3 & 531 & 4.899 & 0.264 & 515 & 3.78 & 0.182 & 537 & 5.546 & 0.337 \\
\hline SP4 & 2059 & 3.333 & 0.25 & 1971 & 2.79 & 0.193 & 2174 & 4.352 & 0.306 \\
\hline SP5 & 1190 & 4.084 & 0.142 & 1291 & 2.289 & 0.248 & 1265 & 7.049 & 0.187 \\
\hline SP6 & 2726 & 6.713 & 0.229 & 3154 & 15.347 & 0.279 & 2256 & 3.83 & 0.155 \\
\hline
\end{tabular}

Table 3: Average traffic volume and average $\mathrm{SO}_{2}$ concentrations obtained in ppm using gilair-3 air sampler

\begin{tabular}{|c|c|c|c|c|c|c|}
\hline & Morning & & Afternoon & & Evening & \\
\hline $\begin{array}{l}\text { Sampling } \\
\text { points }\end{array}$ & $\begin{array}{l}\text { Average } \\
\text { Traffic } \\
\text { Volume }\end{array}$ & $\begin{array}{l}\text { Mean } \mathrm{SO}_{2} \\
(\mathrm{ppm})\end{array}$ & $\begin{array}{l}\text { Average } \\
\text { Traffic } \\
\text { volume }\end{array}$ & $\begin{array}{l}\text { Mean } \mathrm{SO}_{2} \\
(\mathrm{ppm})\end{array}$ & $\begin{array}{l}\text { Average } \\
\text { Traffic } \\
\text { volume }\end{array}$ & $\begin{array}{l}\text { Mean } \mathrm{SO}_{2} \\
(\mathrm{ppm})\end{array}$ \\
\hline SP1 & 397 & 0.065 & 366 & 0.053 & 432 & 0.095 \\
\hline SP2 & 695 & 0.05 & 660 & 0.043 & 677 & 0.044 \\
\hline SP3 & 531 & 0.091 & 515 & 0.059 & 537 & 0.097 \\
\hline SP4 & 2059 & 0.068 & 1971 & 0.049 & 2174 & 0.075 \\
\hline SP5 & 1190 & 0.037 & 1291 & 0.074 & 1265 & 0.057 \\
\hline SP6 & 2726 & 0.061 & 3154 & 0.076 & 2256 & 0.051 \\
\hline
\end{tabular}

Table 4: Health problems perceived by the users of the road under study

\begin{tabular}{lcl}
\hline Received health problems & Frequency & Percentage \\
Cough & 5 & 12.5 \\
Poor breathing & 7 & 17.5 \\
Chest pain & 6 & 15 \\
Respiratory tract infection & 6 & 15 \\
Fever & 4 & 10 \\
Headache & 5 & 12.5 \\
Others* & 7 & 17.5 \\
Total & $\mathbf{4 0}$ & $\mathbf{1 0 0}$ \\
\hline
\end{tabular}

*represent other health problems that are less relevant to the study

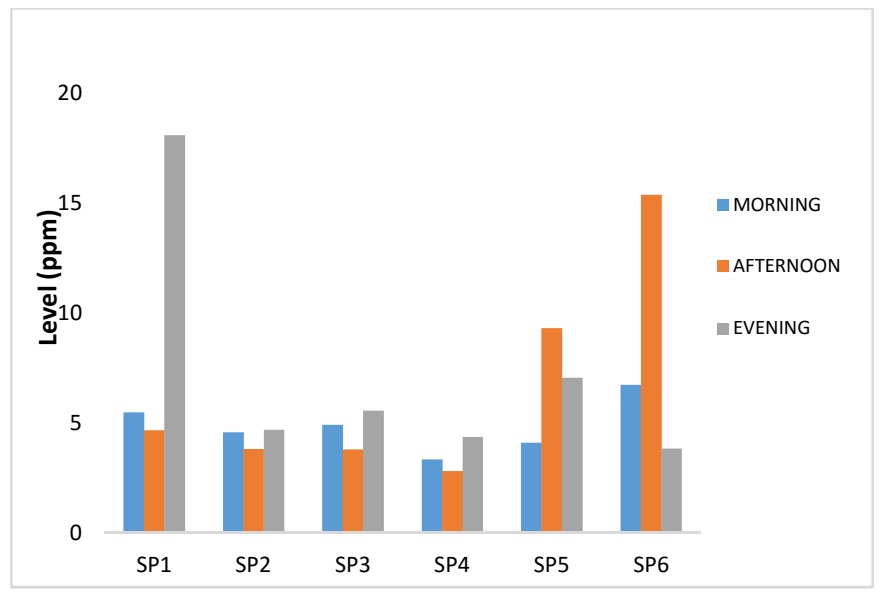

Figure 4: Mean carbon (ii) oxide (CO) levels across periods at the six

(6) sampling points using MSA altair $5 x$ multi gas sensor 


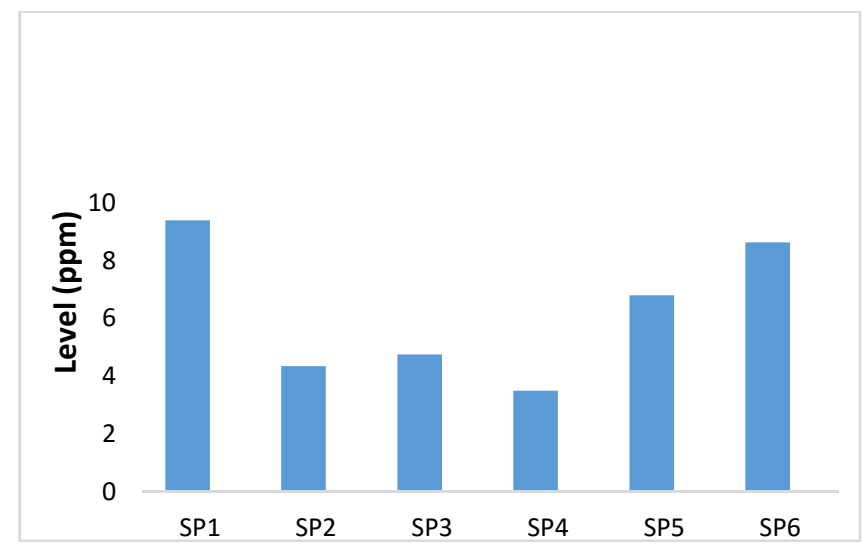

Figure 5: Daily mean of carbon (ii) oxide (CO) levels per three days at each sampling point using altair $5 \mathrm{x}$ multi gas sensor

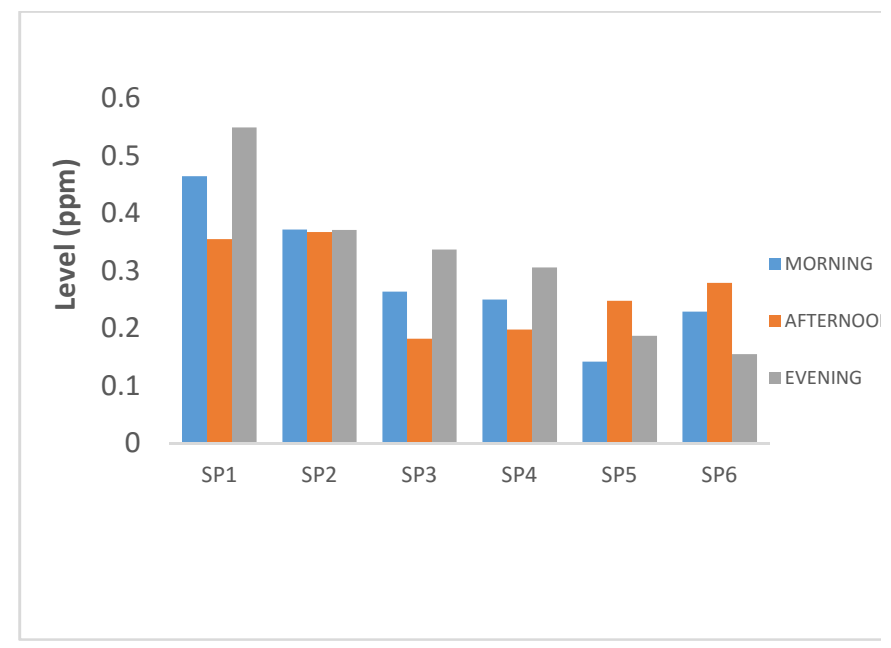

Figure 6: Mean sulphur (iv) oxide $\left(\mathrm{SO}_{2}\right)$ levels across periods at the three (3) sampling points using MSA altair $5 x$ multi gas sensor

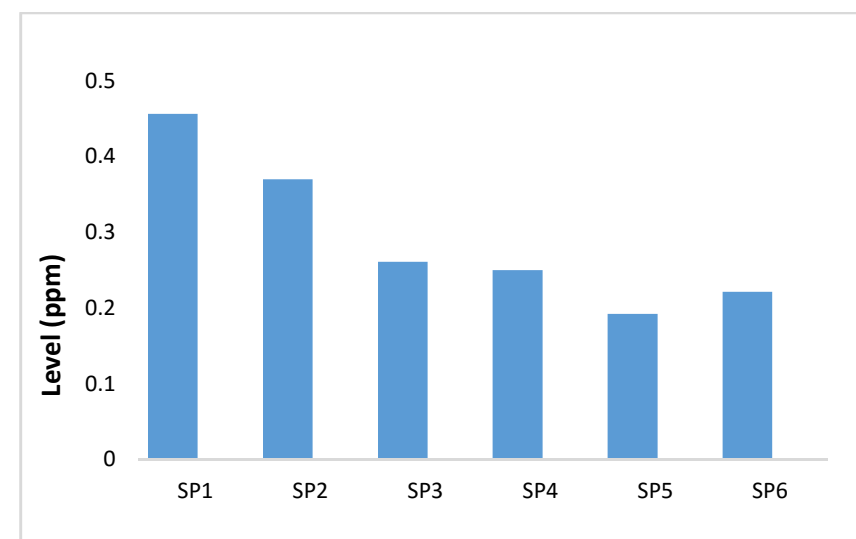

Figure 7: Daily mean of sulphur (iv) oxide $\left(\mathrm{SO}_{2}\right)$ levels per three days at each sampling point using altair $5 \mathrm{x}$ multi gas sensor

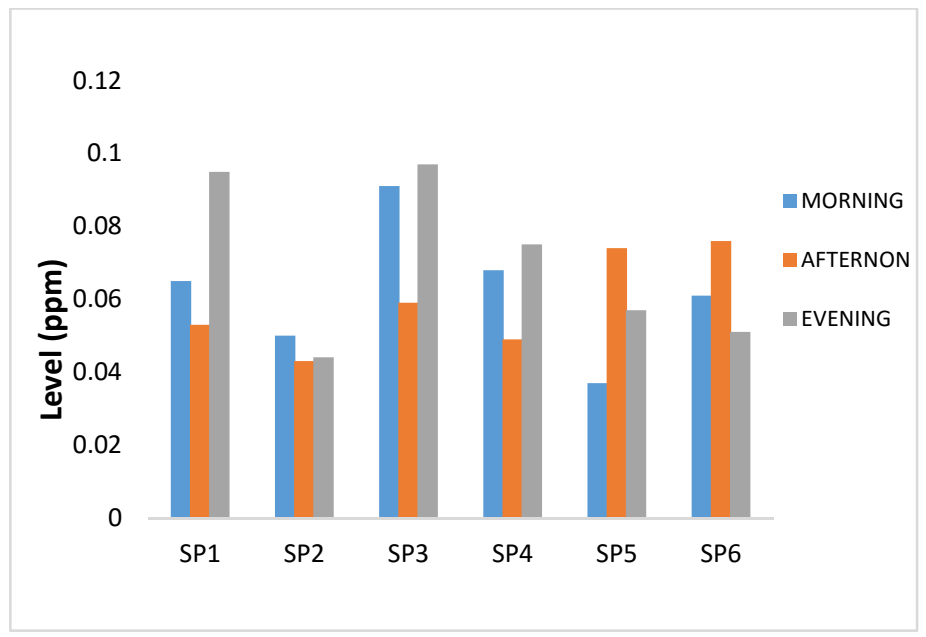

Figure 8: Mean Sulphur (iv) oxide $\left(\mathrm{SO}_{2}\right)$ levels across periods at the three (3) sampling points using gilair 3 air sampler

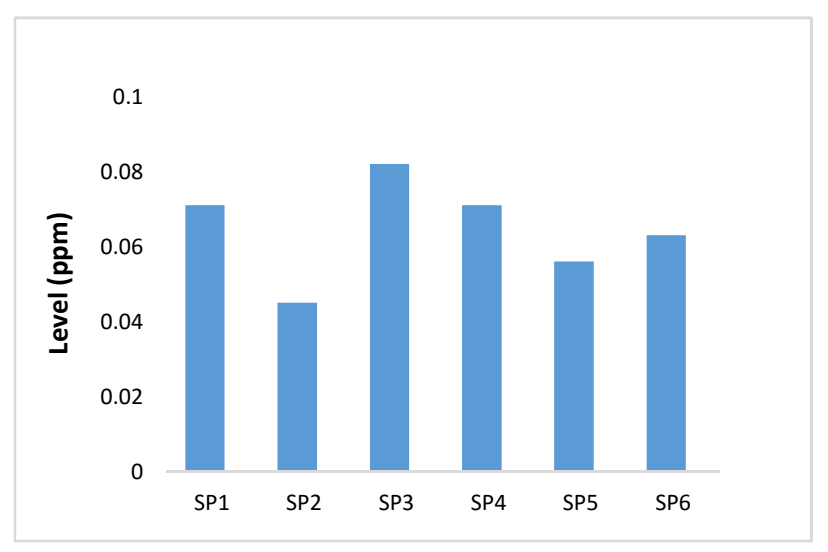

Figure 9: Daily mean of sulphur (iv) oxide $\left(\mathrm{SO}_{2}\right)$ levels per three days at each sampling point using gilair 3 air sampler

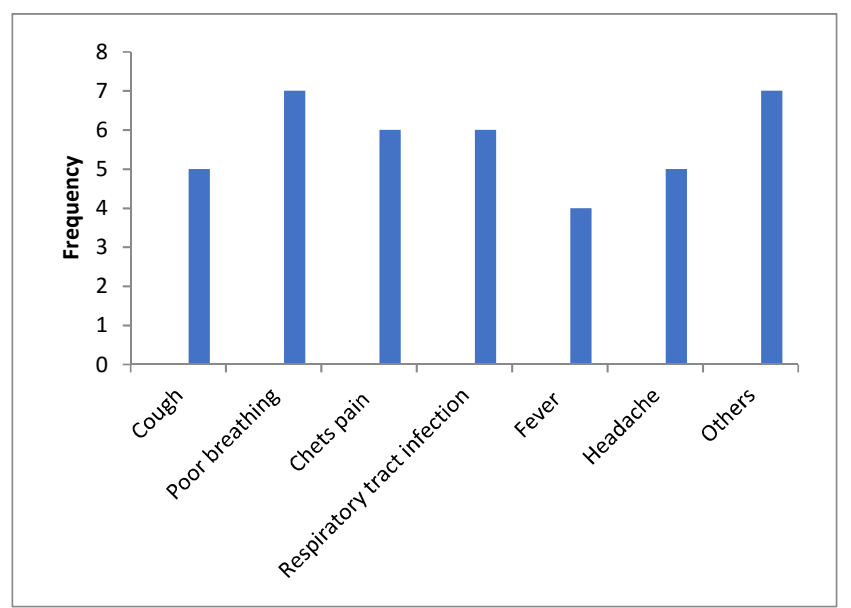

Figure 10: The various health problems perceived by the respondents of the questionnaires and their frequencies 


\subsection{Discussion}

\subsection{Ambient air pollution along Ilorin-Lagos Highway}

Table 2 showed the average traffic volume and average concentrations of both carbon (ii) oxide (CO) and sulphur (iv) oxide $\left(\mathrm{SO}_{2}\right)$ obtained in ppm per three days at the six sampling points using altair $5 \mathrm{x}$ multi gas sensor. In the morning and the evening peak hours, the traffic volume was high at some of the sampling points SP1, SP2, SP3, and SP4 compared to the afternoon off-peak hours. The high traffic volume recorded was due to the importance of the route under study because it is the major road linking the North and the South west Nigeria. This reason makes the road to be congested with vehicles, buses, cars and bikes.

The traffic volume had great impact on the concentration levels of CO obtained especially at sampling points SP1, SP3, SP4 and SP5, because high traffic volume corresponded to high pollutant level while the impact was felt at all the sampling points by the concentration levels of $\mathrm{SO}_{2}$. The relationship exhibited between the traffic volume and the pollutants concentration at almost all the sampling points for both $\mathrm{CO}$ and $\mathrm{SO}_{2}$ levels was in accordance with the results obtained by Oguntoke and Yusuf (2008) where the variation in pollutants concentrations was attributed to the variation in traffic volume.

The lowest level of $\mathrm{CO}$ and $\mathrm{SO}_{2}$ were both obtained at SP5 during afternoon and morning respectively, this may be attributed to the speed with which the vehicles were moving at this point because the road is very good and straight without any bend. The highest level of $\mathrm{CO}$ and $\mathrm{SO}_{2}$ were both obtained at SP1 during evening, the reason may be traced to the slow speed with which vehicles were moving because the point is very close to Eyenkorin garage which is usually crowded with people engaging in different commercial activities such as hawking, loading of vehicles with goods and passengers etc. Near to this point is also a round about where vehicles need to slow down.

The concentrations of $\mathrm{CO}$ at all six sampling points ranged between 2.289 and $18.055 \mathrm{ppm}$ while the concentrations of $\mathrm{SO}_{2}$ at all six sampling points ranged between 0.142 and $0.550 \mathrm{ppm}$.

The mean concentration range of $\mathrm{CO}$ pollutants all sampling points were found to be within the FEPA standard (10 ppm for 1-hour limit and $20 \mathrm{ppm}$ for 8-hour limit) and USEPA standard (35 ppm for 1-hour limit). However, the concentration range of $\mathrm{SO}_{2}$ obtained at all sampling points is lower than those reported in similar studies conducted by Ayodele and Abubakar (2010), Ettouney et al. (2010), and Kalabokas et al. (1999), in Lagos (3.21 - 5.18 ppm), Port-Harcourt (7.4 - $15.5 \mathrm{ppm})$ and Greece $(16-64 \mathrm{ppm})$ respectively, but was higher than the range of $0.03-0.09$ ppm reported in Kano metropolis, Nigeria (Okunola et al., 2012). The mean concentration of $\mathrm{SO}_{2}$ pollutant was found to be much higher when compared with FEPA limit (0.01 ppm for 1-hour limit and $0.1 \mathrm{ppm}$ for 24-hour limit).

Table 3 showed the average traffic volume and average sulphur (iv) oxide, $\left(\mathrm{SO}_{2}\right)$ concentrations obtained in ppm per three days at the six sampling points using gilair-3 air sampler. The traffic volume had great impact on the concentration levels of $\mathrm{SO}_{2}$ obtained, because high traffic volume corresponded to high pollutant level at all the sampling points. The relationship exhibited between the traffic volume and the pollutant concentration at all the sampling points was in accordance with the results obtained by Oguntoke and Yusuf (2008) where the variation in pollutants concentrations was attributed to the variation in traffic volume.

The range of $\mathrm{SO}_{2}$ concentration was found to be $0.037-0.097 \mathrm{ppm}$ and this is lower than ranges of $0.04-0.15 \mathrm{ppm}, 3.21-5.18 \mathrm{ppm}, 7.4$ - $15.5 \mathrm{ppm}$, and 16 - $64 \mathrm{ppm}$ as reported in similar studies conducted by Abam and Unachukwu (2009), Ayodele and Abubakar (2010), Ettouney et al. (2010), and Kalabokas et al. (1999), in selected area in Calabar, Lagos, Port-Harcourt and Greece respectively, but was higher than the range of $0.03-0.09$ ppm reported in Kano metropolis Nigeria (Okunola et al., 2012). This was slightly higher when compared with the Federal Environment Protection Agency limit especially the lower limit standard.

Figure 4 shows the mean level of carbon (ii) oxide (CO) obtained across periods at the six sampling points using altair $5 \mathrm{x}$ multi gas sensor. The figure indicated that the highest level of $\mathrm{CO}$ was recorded during the evening period at SP1, SP2, SP3 and SP4 and afternoon period at SP5 and SP6. The values of their concentrations were indicated to be $18.055 \mathrm{ppm}, 4.675 \mathrm{ppm}, 5.546 \mathrm{ppm}, 4.352 \mathrm{ppm}, 9.289 \mathrm{ppm}$ and 15.347 ppm respectively. This could be as a result of high traffic volume in the afternoon at SP5 and SP6.

The least level of $\mathrm{CO}$ was indicated in the figure to be obtained during: the afternoon period at SP1, SP2, SP3, and SP4; morning period at SP5 and evening period at SP6. The values of their concentrations were found to be $4.663 \mathrm{ppm}, 3.798 \mathrm{ppm}, 3.780 \mathrm{ppm}, 2.790 \mathrm{ppm}, 4.084 \mathrm{ppm}$ and $3.830 \mathrm{ppm}$ respectively.

Figure 5 showed the daily mean of carbon (ii) oxide (CO) concentration obtained for the whole three days used at each sampling point using altair $5 \mathrm{x}$ multi gas sensor. The concentrations were indicated to be 9.398 ppm, 4.344 ppm, 4.750 ppm, 3.492 ppm, 6.807 ppm and 8.630 ppm at SP1, SP2, SP3, SP4, SP5 and SP6 respectively.

It will be seen that all of them were below FEPA hourly standard, indicating a good air quality with respect to CO level at all the six sampling points.

Figure 6 showed the mean level of sulphur (iv) oxide $\left(\mathrm{SO}_{2}\right)$ obtained across periods at the six sampling points using altair $5 \mathrm{x}$ multi gas sensor. The figure indicated that the highest levels of $\mathrm{SO}_{2}$ were obtained during: the evening period at SP1, SP3 and SP5; afternoon at SP4 and SP6; and morning period at SP2. The values of their concentrations were indicated to be $0.550 \mathrm{ppm}, 0.337 \mathrm{ppm}, 0.306$ ppm, $0.248 \mathrm{ppm}, 0.279 \mathrm{ppm}$ and $0.372 \mathrm{ppm}$ respectively.

The concentrations of CO were lowest in the morning period at SP4 (0.142 ppm), in the afternoon period at SP3 (0.182 ppm), SP4 (0.193 ppm), SP1 (0.355 ppm), SP2 (0.368 ppm) and in the evening period at SP6 $(0.155 \mathrm{ppm})$. The variations could be linked to the traffic volume at different points of sampling.

Figure 7 showed the daily mean of sulphur (iv) oxide $\left(\mathrm{SO}_{2}\right)$ concentration obtained for the whole three days used at each sampling 
point using altair $5 \mathrm{x}$ multi gas sensor. The concentrations were indicated to be $0.456 \mathrm{ppm}, 0.370 \mathrm{ppm}, 0.261 \mathrm{ppm}, 0.250 \mathrm{ppm}, 0.192$ ppm and $0.221 \mathrm{ppm}$ at SP1, SP2, SP3, SP4, SP5 and SP6 respectively. It will be seen that all the obtained concentrations were above FEPA standard, indicating a poor air quality with respect to $\mathrm{SO}_{2}$ level at all the six sampling points.

Figure 8 showed the mean level of sulphur (iv) oxide $\left(\mathrm{SO}_{2}\right)$ obtained across periods at the six sampling points using gilair 3 air sampler. The figure 9 indicated that the highest levels of $\mathrm{SO}_{2}$ were obtained during: the evening period at SP1 $(0.095 \mathrm{ppm}), \mathrm{SP} 3(0.075 \mathrm{ppm})$ and SP4 $(0.074 \mathrm{ppm})$; afternoon at SP5 (0.076 ppm) and SP6 (0.050 ppm); and morning at SP6. The least level of $\mathrm{CO}$ was indicated in the figure to be obtained during: the afternoon period at SP1 (0.053 ppm), SP2 (0.043 ppm), SP3 (0.059 ppm) and SP4 (0.049 ppm); morning period at SP5 $(0.037 \mathrm{ppm})$ and evening period at SP6 (0.051 ppm).

Figure 9 showed the daily mean of sulphur (iv) oxide $\left(\mathrm{SO}_{2}\right)$ concentration obtained for the three days used at each sampling point using gilair 3 air sampler. The concentrations were indicated to be 0.045 ppm, 0.056 ppm, 0.063 ppm, 0.071 ppm, 0.071 ppm, and 0.082 ppm at Arinkinkin, Saapade, Bergger, Eyenkorin, Methodist and Atiba respectively. It was seen that all the obtained concentrations were above the NESREA lower limit standard but below the upper limit standard.

\subsection{In-vehicule air pollution along Ilorin-Lagos road}

The concentration levels obtained for $\mathrm{CO}$ and $\mathrm{SO}_{2}$ inside the vehicle were $6.32 \mathrm{ppm}$ and $0.126 \mathrm{ppm}$ under opened-window condition and $9.53 \mathrm{ppm}$ and $0.274 \mathrm{ppm}$ respectively under closed-window condition. Comparing the pollutants levels with the FEPA standards, it was observed that $\mathrm{CO}$ levels were below the FEPA permissible limit while $\mathrm{SO}_{2}$ levels were both above the standard.

Comparing the levels of both $\mathrm{CO}$ and $\mathrm{SO}_{2}$ under opened and closed window conditions it was found that the levels of both pollutants under opened window condition were lower than the levels under closed window condition. This was in concord with the results obtained by Potchter et al. (2014) in the Tel Aviv metropolitan area, Israel that commuters in cars with closed windows were exposed to the highest mean CO level, $27.2 \mathrm{ppm}$, for a period of $38 \mathrm{~min}$; those in a car with open windows, to $19.7 \mathrm{ppm}$ over the same period.

\subsection{Questionnaire Analysis}

The questionnaire prepared contained much information ranging from vehicles maintenance routine, driver's health conditions, and mode of cooking. 50 questionnaires were distributed among the drivers at different motor parks such as Saw-mill, Kasmag, young legacy and Iyana-Ipaja motor parks. Only 40 questionnaires were collected and responded to accordingly.

Smokers and non-smokers were found among the respondent who are drivers at the visited parks, majority of whom claimed to have been using the road for more than three years. According to the information supplied, majority of them service their vehicles regularly at the maximum interval of three weeks while fewer do theirs at irregular intervals. Motorists of the road under study (Table 4) perceived cough
(12.5\%), poor breathing (17.5\%), chest pain (15\%), respiratory tract infection (15\%), fever (10\%), headache (12.5\%), and others (17.5\%) as the major health risks associated with exposure to pollutants.

Figure 10 showed the various health problems perceived by the respondents of the questionnaires and their frequencies. The health problems range from cough to poor breathing, chests pain, respiratory tract infection, fever, headache and others.

\subsection{Conclusion and Recommendations}

The overall situation regarding motor vehicle emissions along IlorinLagos road is poor with a potential human health effect. It is clear from the results that the Altier 5X Multigas sensor is effective only for the in-vehicle measurement probably because it is point source while Gliar 3 performed better for ambient measurement i.e. area source. The results revealed that motor vehicle emissions along Ilorin-Lagos road include pollutants like $\mathrm{CO}$, and $\mathrm{SO}_{2}$. The levels of the $\mathrm{CO}$ measured at all the sampling points were below the NESREA permissible limit. Therefore, in this aspect air quality is good and not hazardous to health. The trees along the path should be maintained.

$\mathrm{SO}_{2}$ measured using altair $5 \mathrm{x}$ multi gas sensor, they were above the NESREA permissible limit at all the sampling points while for $\mathrm{SO}_{2}$ measured using gilair-3 air sampler, they were above the NESREA lower limit but did not exceed the upper safe limit at all the sampling points. Therefore, in this aspect air quality is not safe and it is hazardous to health.

This study also revealed that gaseous pollutants in the air, such as $\mathrm{CO}$, and $\mathrm{SO}_{2}$ directly or indirectly threaten the environment and life of Ilorin-Lagos road users and that motor vehicles emission and may be other related activities carried out along this highway (beyond the scope of this study) remain the sources of these pollutants. This implies that vehicular emissions along this road are significant with potentially hazardous health consequences. Based on the pollution levels and health implications detailed in this study, it is important to formulate policies and set up a monitoring program to reduce vehicular emissions and protect the health of road users on Nigeria highways. Regular maintenance and rehabilitation of roads and bridges on these motor highways can be valuable to facilitate the speed with which vehicles will be moving, reduce congestion of vehicles on major roads, which in turn will help reduce the levels of pollutants. Finally, motorization growth should be largely checked by environmental regulations and build, along use of rails should be encouraged where the population is high.

\section{Conflict of Intrest}

Authors declare no conflict of interest

\section{Authors Contribution}

Conception and design: MAOA

Execution: MAOA and KOA

Interpretation: MAOA and $\mathrm{KOA}$

Writing of Paper: MAOA, KOA and OAA 


\section{References}

Abam F.I. and Unachuku G.O., 2009, Vehicular Emissions and Air Quality in Nigeria, European Journal of Scientific Research, 34 (4): 550560. http://www.eurojounals.com/ejsr_34_4_11.pdf

Abdul Raheem A.M.O., Adekola F.A., and Obioh I.B., 2009, Monitoring of Sulfur Dioxide in The Guinea Savanna Zone of Nigeria: Implications of the Atmospheric Photochemistry. Chemical Society of Ethiopia, 23 (3): 001-008

Ajayi, A. B. and Dosunmu, O. 0., 2002, Environmental hazards of importing used vehicles into Nigeria, In: Proceedings of International Symposium on Environmental Pollution Control and Waste Management, January 7-10, Tunis, 521-532.

Atubi, A. 0., 2015, Transport and the environment: towards reducing road traffic emissions in Nigeria, International Journal of Science and Technology, 4 (1): 58-78.

Ayodele, J. T. and Abubakar, F., 2010, Sulphur Dioxide as Indoor Pollutant in Kano Municipality Kano-Nigeria, Journal of Environmental Chemistry and Eco-toxicology, 2 (1): 9-13.

Biggeri A., Bellini P. and Terracini B., 2004. Meta-analysis of the Italian studies on short-term effects of air pollution-MISA 1996-2002, Epidemiol, Prev. 28, 4-100.

Delfino, R., Wu, J., 2012, In-vehicle Air Pollution Exposure Measurement and Modeling. Final Report California Air Resources Board Contract No. 07-310

Dominici, F., Peng, R.D., Bell, M.L., Pham, L., McDermott, A., Zeger, S.L., Samet, J.M., 2006, Fine particulate air pollution and hospital admission for cardiovascular and respiratory diseases, JAMA 295: 1127-1134.

Ebtekar, M., 2006, Air pollution induced asthma and alterations in cytokine patterns, Iran. J. Allergy Asthma Immunol, 5: 47-56.

Estevez-Garcia, J.A., Rojas-Roa, N.Y., Rodriguez-Pulido, A.I., 2013, Occupational exposure to air pollutants: Particulate matter and respiratory symptoms affecting traffic-police in Bogota, Rev. Salud Publica (Bogota), 15: 889-902.

Ettouney H, Alhaddad A, Saqer S., 2010, Emission rate model and predictions of air pollution in Kuwait, Chemical Engineering Department Kuwait University P.O.Box 5969 - Safat 13060.

Ham, W., Vijayan, A., Schulte, N., Herner, J. D., 2017, Commuter Exposure to PM2.5, BC, and UFP in six common Transport microenvironments in Sacramento, California. Atmospheric Environment 167: 335-345.

Han, X. and Naeher, L., 2006, A Review of Traffic-Related Air Pollution Exposure Assessment Studies in the Developing World, Environment International Conference, 2006 January, 30.

Kalabokas, P. O., Viras, L. G. and Repapis, C., 1999, Analysis of the 11 Years record (1987 - 1997) of Air Pollution Measurements in Athens, Greece, Part I: Primary Air Pollutants, Global Nest Journal, 1(3): 157 167.

Magbagbeola N. O., 2001, The use of Economic Instruments for Industrial pollution Abatement in Nigeria: Application to the Lagos
Lagoon, Selected papers, Annual Conferences of the Nigerian Economic Society held in Port-Harcourt.

Oguntoke O. and Yussuf A. S., 2008, Air pollution arising from Vehicular Emissions and the Associated Human Health Problems in Abeokuta Metropolis, Nigeria, An international Journal of Agricultural Sciences, Sciences, and Environment and Technology, 8(2): 15-24.

Ojo 0.O.S. and Awokola O.S., 2012, Investigation of Air Pollution from Automobiles at Intersections on Some Selected Major Roads in Ogbomoso, South Western, Nigeria IOSR Journal of Mechanical and Civil Engineering (IOSRJMCE), 1 (4): 31-35.

Okunola O. J., Uzairu A., Gimba C. E. and Kagbu J. A., 2012, Assessment of Gaseous Pollutant along High Traffic Roads in Kano, Nigeria, International Journal of Environment and Sustainability, 1 (1): 1572 1590.

Peters A., von Klot S., Heier M., Trentinaglia I., Hörmann A., Wichmann H.E., Löwel H. 2004, In: Exposure to Traffic and Onset of Myocardial Infarction, Cooperative Health Research in the Region of Augsburg Study Group 351.

Pope 3rd, C.A., Turner, M.C., Burnett, R.T., Jerrett, M., Gapstur, S.M., Diver, W.R., Krewski, D., Brook, R.D., 2015, Relationships between fine particulate air pollution, cardiometabolic disorders, and cardiovascular mortality, Circ. Res. 116: 108-115.

Potchter, O., Oz, M.S., Yaakov, Y., and Schnell, I., 2014, Exposure of motorcycle, car and bus commuters to carbon monoxide on a main road in the Tel Aviv metropolitan area, Israel, Environmental Monitoring and Assessment 186 (12), published by Springer International Publishing Switzerland, DOI: 10.1007/s10661-0144013-1.

Rivas I., Kumar, P., Hagen-Zanker, A., 2017, Exposure to air pollutants during commuting in London: Are there inequalities among different socio-economic groups? Environment International, 101: 143-157.

Sharma, S.B., Jain, S., Khirwadkar, P., Kulkarni, S., 2013, The Effects of Air Pollution on the Environment and Human Health, Indian Journal of Research in Pharmacy and Biotechnology 1(3): 391-396.

Tonne, C., Melly, S., Mittleman, M., Coull, B., Goldberg, R., Schwartz, J., 2007, A case control analysis of exposure to traffic and acute myocardial infarction, Environ. Health Perspect, 115 (1): 53-57, http://dx.doi.org/10.1289/ehp.9587.

USEPA, 2006., (United State Environmental Protection agency), Provisional Assessment of Recent Studies on Health Effects of Particulate Matter Exposure, National Center for Environmental Assessment, Research Triangle Park, NC 27711, EPA/600/R-06/ 063.

USEPA, 1998, Guidelines for Neurotoxicity Risk Assessment, EPA/630/R-95/001F, Apr 1998.

http://www.epa.gov/raf/publications/guidelines-neurotoxicityriskassessment.

WHO, 2000, Air quality Guidelines for Europe, World Health Organization Regional Office for Europe, Copenhagen.

World Health Organization, 2005, Health Effects of Transport-Related Air Pollution; WHO: Geneva, Switzerland. 
World Health Organization, (WHO), 2001, Strategy on Air Quality andHealth Occupational and Environmental Health Protection of the Human Environment, World Health Organization, Geneva.

Zhu, Y., Hinds, W.C., Kim, S., Sioutas, C., 2002, Concentration and size distribution of ultrafine particles near a major highway, J. Air Waste Manag. Assoc, 52: 1032-1042.
Zmirou D., Gauvin S., Pin I., Momas I., Sahraoui F., Just J., Le Moullec Y., Bremont F., Cassadou S. and Reungoat P., 2004, Traffic related air pollution and incidence of childhood asthma, Results of the vesta case control study, J. Epidemiol, Community Health, 58: 18-23. 